\title{
A Plasmid of Streptomyces coelicolor Carrying a Chromosomal Locus and its Inter-specific Transfer
}

\author{
By D. A. HOPWOOD AND HELEN M. WRIGHT \\ John Innes Institute, Colney Lane, Norwich NOR $70 \mathrm{~F}$
}

(Received I 8 July 1973)

\begin{abstract}
SUMMAR Y
A strain of Streptomyces coelicolor A3(2) was selected in which the wild-type autonomous SCPI plasmid had acquired an insertion of a region of the host chromosome bearing the $c y s B$ locus. This strain, called an $\mathrm{SCPI}^{\prime}$ strain by analogy with $\mathrm{F}^{\prime}$ strains of Escherichia coli, donated the $c y s B^{+}$allele very efficiently to a cys $B$ recipient. The Cys ${ }^{+}$progeny of such crosses were heterozygotes that gave rise to $\mathrm{Cys}^{-}$segregants by plasmid loss. Other donor markers, not carried on the plasmid, were donated with much lower frequencies. The SCPI-cysB plasmid was also donated rather efficiently to a strain of Streptomyces lividans, previously shown to receive the wild-type SCPI plasmid. Transfer back from $S$. lividans to $S$. coelicolor A3(2) occurred at a very much lower frequency.
\end{abstract}

\section{INTRODUCTION}

A plasmid, shown by genetic evidence to be present in the wild-type A3(2) of Streptomyces coelicolor, has been called SCPI (Vivian, 197I). SCPr is transferred very efficiently from strains (designated IF) that carry it in the autonomous state to strains lacking it, which are designated Uf (Vivian, I97I ; Puglia, Spada-Sermonti, Basile, Misuraca \& Sermonti, 1973). It is also transferred, at a lower frequency, to at least one other species of the genus Streptomyces (Hopwood \& Wright, 1973a).

Various types of strains capable of efficient donation of chromosomal markers to UF cultures have been derived from IF strains. In the NF type (Hopwood, Harold, Vivian \& Ferguson, 1969) the plasmid appears to be stably associated with the chromosome at the 9 o'clock position on the circular linkage map. When it is transferred to a UF strain, as occurs with a very high frequency, fragments of donor chromosome extending for varying distances on either side of the 9 o'clock position are also transferred. The result is that chromosomal markers near to 9 o'clock are donated very efficiently, whilst more distant markers are donated less frequently. In other types of donor (Vivian \& Hopwood, 1973) the plasmid appears to interact transiently with the donor chromosome at positions characteristic of particular donors. The plasmid, and donor markers close to its point of interaction with the chromosome on one side only, are transferred efficiently from such donors to UF strains. The efficiency of transfer of markers decreases with increasing distance from the point of interaction with the plasmid.

Vivian \& Hopwood (1973) explained the behaviour of their donors on the hypothesis that such strains contained a substituted plasmid, analogous with that in a merodiploid $\mathrm{F}^{\prime}$ strain of Escherichia coli (Jacob \& Adelberg, I959; Adelberg \& Burns, 1960). On this hypothesis, a piece of chromosome had been inserted into SCPI and chromosomal mobilization occurred because the homology between the chromosomal insertion and the 
corresponding region of the complete chromosome allowed interaction by a process perhaps resembling 'donor crossing-over' (Campbell, 1962).

Recombinant progeny produced in crosses of these donors with UF strains, like recombinants derived from NF $\times$ UF crosses, showed no evidence of persistent heterozygosity of any markers; presumably the chromosomal fragments transferred to UF recipients in such crosses were incapable of autonomous replication in the recipient, and recombinants arose only as a result of integration of donor markers into a haploid genome by crossing-over. Thus the chromosomal insertion into SCPI, postulated to have occurred in the origin of these donors, did not carry alleles of any of the markers that were involved in the crosses. This conclusion was also indicated by the fact that no marker was found to be transferred with a frequency as high as that of plasmid transfer itself; the highest frequency of marker transfer approached $50 \%$ when plasmid transfer was virtually $100 \%$ efficient (Vivian \& Hopwood, 1973).

A prediction of the hypothesis of Vivian \& Hopwood (1973) was that donors should occur in which the chromosomal insertion into SCPI would carry a recognizable marker. The present paper describes the isolation and characteristics of such a strain. A brief report of its occurrence has already been made (Hopwood \& Wright, I973 $b$ ).

\section{METHODS}

General. Complete (CM) and minimal (MM) media and standard cultural and genetic techniques with Streptomyces coelicolor were those described by Hopwood (I967). All incubations were at $30^{\circ} \mathrm{C}$.

Strains. The interrelations of the chief strains referred to are described in the text and are summarized in Fig. I. Strain A3(2) is the wild type of Streptomyces coelicolor used in most previous genetic studies (see Hopwood, Chater, Dowding \& Vivian, 1973). Strain I 326 is 'strain 66' of Lomovskaya, Mkrtumian, Gostimskaya \& Danilenko (I972), described as $S$. lividans by Krasilnikov (1965) and kindly supplied by Dr N. D. Lomovskaya, Institute of Genetics and Selection of Micro-organisms, Moscow, U.S.S.R. Auxotrophic mutants of I 326 were isolated following mutagenesis by $N$-methyl- $N^{\prime}$-nitro- $N$-nitrosoguanidine (NTG) according to the procedure of Delić, Hopwood \& Friend (I970).

Ultraviolet irradiation. This was done as described by Harold \& Hopwood (I970). The dose was approx. $3800 \mathrm{ergs} / \mathrm{mm}^{2}$.

Testing of fertility and of the presence of SCP1 by 'plate-crossing'. The indirect selection procedure of Sermonti \& Casciano (1963), as modified by Hopwood et al. (1969) and Vivian \& Hopwood (I970), was used to assess the proficiency of recombinant production ('fertility') of combinations of strains. In the recognition of SCPI, use was made of the fact that strains carrying it inhibit aerial mycelium development on the part of UF strains by the production of a diffusible substance (Vivian, I97I). Such inhibition was assessed by replicating the strains to a 'lawn' of spores of UF tester strain II90 (hisAI uraAI strAI) on CM and incubating the resulting 'plate-crosses' for $2 \frac{1}{2}$ to 3 days. Strain II90 was a particularly good indicator of the presence of the sporulation inhibitor, which gave rise to non-sporulating and non-pigmented zones on the plate-crosses.

Isolation of donor strain I873. The procedure was that of Vivian \& Hopwood (1973). The parent was IF strain I 2 (phe $A \mathrm{I}$ ) and, for reasons outlined below, the tester was UF strain A694 (cysB). 


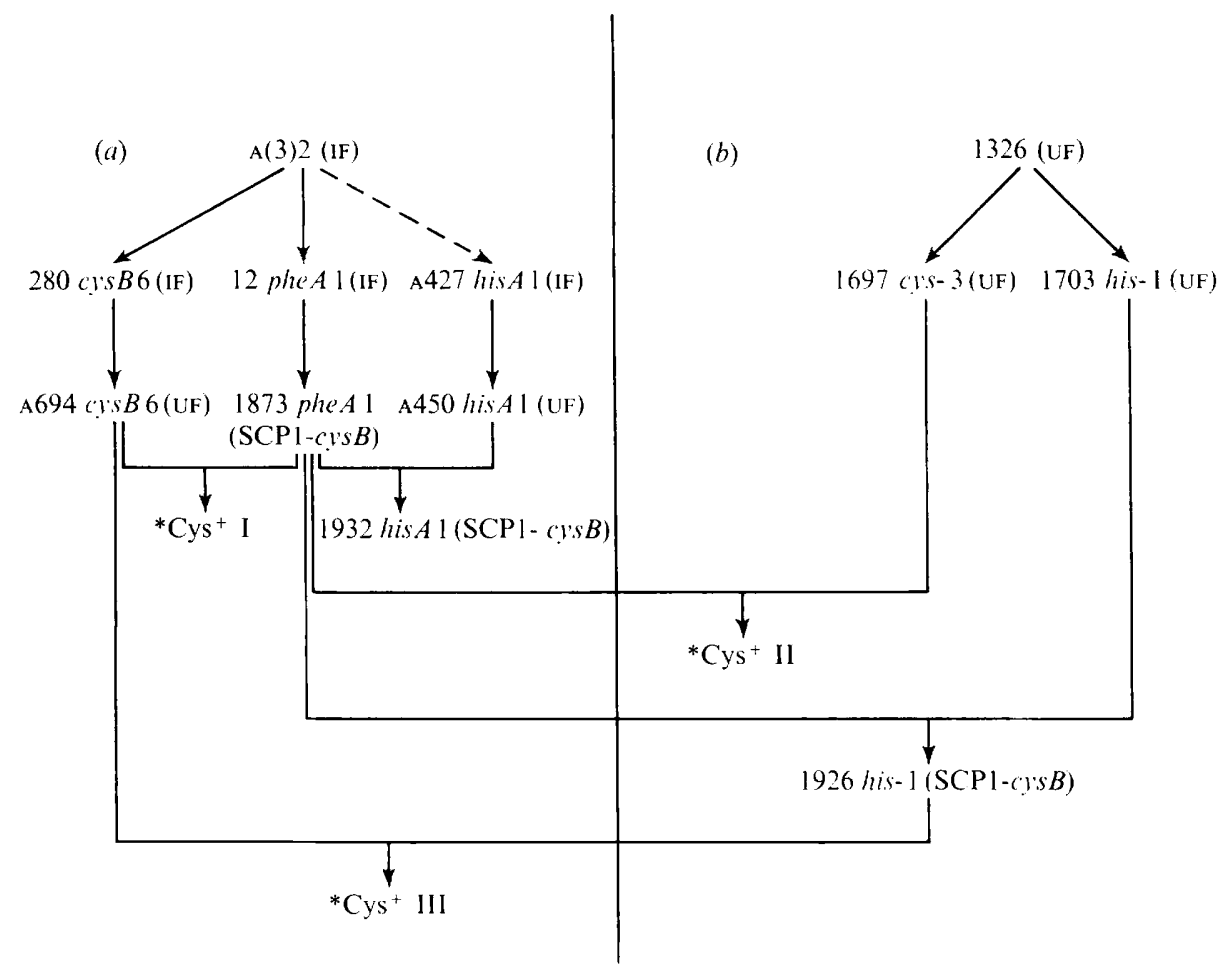

Fig. I. Derivation, from (a) Streptomyces coelicolor A3(2) or (b) S. lividans 1326 , of the chief strains referred to in this paper, and their interrelationships. Asterisks denote the three kinds of Cys ${ }^{+}$ heterozygotes described in Table 3.

\section{RESULTS}

Isolation and preliminary characterization of the cys $B^{+}$donor. Strain $\mathrm{I} 2$ (pheA $\mathrm{I}: \mathrm{IF}$ ) was irradiated with u.v. to about $2 \%$ survival and plated to yield about 1000 colonies/plate. These were tested for their capacity to yield prototrophic recombinants in plate-crosses with UF strain A694 (cysB6). This strain was chosen since the $c y s B$ locus lies within a wellmarked region of the linkage map. Thus if a donor in which SCPI carried cys $B^{+}$were obtained, the limits of the chromosomal insertion could be determined by studying markers linked on either side of $c y s B$, and the pattern of donation of other markers on either side of such limits could be studied. Out of about 53000 colonies, 60 were chosen as possibly having a greater capacity than the parent strain for generating prototrophic recombinants. After one round of re-streaking and re-testing, only ro of the 60 strains appeared to donate $c y s B^{+}$at a significantly higher frequency than did the parent If culture. These ten strains were purified and re-tested by further plate-crosses for donation of various wild-type alleles, including $c y s B^{+}$, to a variety of UF strains. All ten strains donated the wild-type alleles of most or all of the tested markers with a frequency which was higher than that of donation of the same alleles by the IF parent strain, but which usually fell far short of the maximum frequency of donation of markers in 'ultra-fertile' crosses (Hopwood et al. 1969): that is in crosses of UF strains with NF strains or with the new donors described by Vivian \& Hopwood (I973). One of the ten strains, stock number I873, was exceptional in donating $c y s B^{+}$with a frequency that seemed even higher than the maximum frequency previously observed in ultra-fertile crosses (Fig. 2). Very efficient donation by 1873 was, 


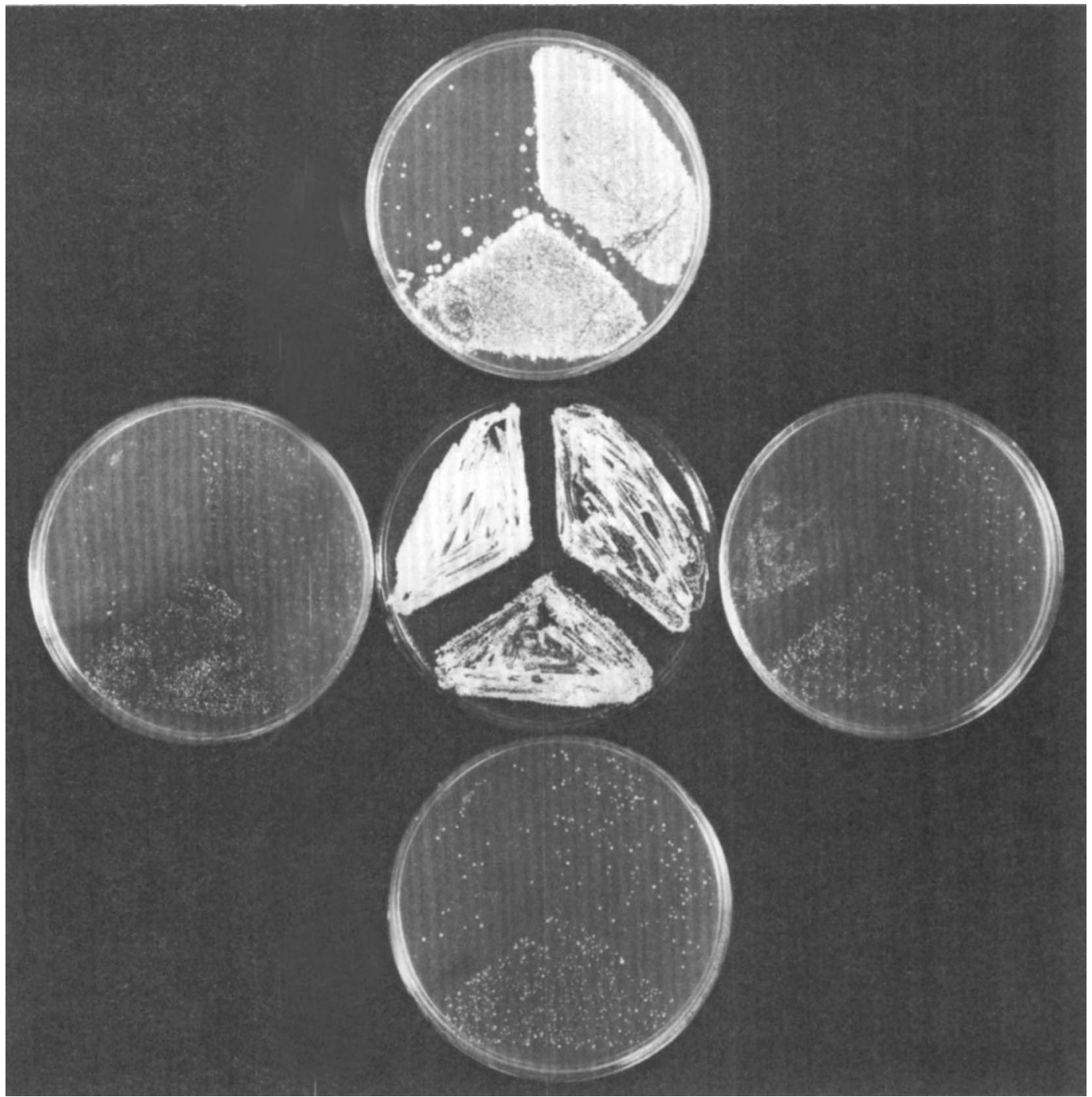

Fig. 2. Donation of four markers to UF strains by IF and SCPI-cysB strains compared. The Petri dish in the centre bears patches of: top left, strain I2 (pheAI IF); top right, I932 (his AI SCPI-cysB); bottom, I 873 ( $p h e A \mathrm{I}$ SCPI-cys $B$ ). This plate was replicated to lawns of UF tester strains and the resulting plate-crosses (not shown) were in turn replicated to the four selective plates placed around the central plate. Each selective plate is counter-selective for the pheA1 or hisA I of the donor

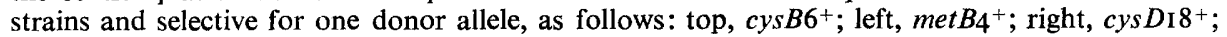
bottom, $\arg A \mathrm{I}^{+}$. Note the massive donation of $c y s B 6^{+}$by the two SCPI-cys $B$ strains and the much lower frequency of donation of the other three markers. The IF strain donates all four markers at low frequency.

however, specific for the $c y s B$ locus out of the series of markers tested. Donation of the wild-type alleles even at loci closely linked to $c y s B$ (for example, met $B$ in Fig. 2) occurred at a much lower frequency. Strain 1873 thus appeared a likely candidate for a strain in which the plasmid SCPI carried a region of the bacterial chromosome including the cys $B$ locus. Further tests, described below, confirmed this interpretation.

Presence of SCPI in the cys $B^{+}$donor. Vivian (I97I) showed that the plasmid SCPI 
Table I. Instability of donors carrying the SCPI-cysB plasmid

Colonies of the two strains, 1873 (pheAI) and 1932 (his $A \mathrm{I}$ ), each carrying the SCPI-cys $B$ plasmid, were tested for their ability to produce $\mathrm{Cys}^{+}$progeny in plate-crosses with strain $\mathrm{A694}$ (cysB6 UF). Two separate experiments are shown for strain 1873 .

\begin{tabular}{|c|c|c|c|c|c|}
\hline \multirow[b]{2}{*}{ Strain } & \multirow[b]{2}{*}{ Treatment } & \multirow{2}{*}{$\begin{array}{c}\text { Survival } \\
(\%)\end{array}$} & \multirow{2}{*}{$\begin{array}{c}\text { Total } \\
\text { no. of } \\
\text { colonies }\end{array}$} & \multicolumn{2}{|c|}{ Non-donor colonies } \\
\hline & & & & Number & Percentage \\
\hline 1873 & $\begin{array}{c}\text { Control } \\
\text { U.V. }\end{array}$ & $\begin{array}{c}(\mathrm{I} 00) \\
\mathrm{I} \cdot 3\end{array}$ & $\begin{array}{l}660 \\
898\end{array}$ & $\begin{array}{l}24 \\
34\end{array}$ & $\begin{array}{l}3 \cdot 6 \\
3 \cdot 8\end{array}$ \\
\hline 1873 & $\begin{array}{c}\text { Control } \\
\text { U.V. }\end{array}$ & $\begin{array}{c}(100) \\
3.9\end{array}$ & $\begin{array}{l}358 \\
78 \mathrm{I}\end{array}$ & $\begin{array}{l}32 \\
45\end{array}$ & $\begin{array}{l}8.9 \\
5 \cdot 8\end{array}$ \\
\hline I 932 & $\begin{array}{c}\text { Control } \\
\text { U.V. }\end{array}$ & $\begin{array}{c}(100) \\
3 \cdot 7\end{array}$ & $\begin{array}{l}29 \mathrm{I} \\
580\end{array}$ & $\begin{array}{l}16 \\
40\end{array}$ & $\begin{array}{l}5.5 \\
6.8\end{array}$ \\
\hline Totals & $\begin{array}{c}\text { Control } \\
\text { U.V. }\end{array}$ & - & $\begin{array}{l}1309 \\
2259\end{array}$ & $\begin{array}{r}72 \\
\text { II } 9\end{array}$ & $\begin{array}{l}5 \cdot 5 \\
5 \cdot 3\end{array}$ \\
\hline
\end{tabular}

confers on strains carrying it the ability to produce a diffusible substance that inhibits the development of UF strains, including aerial mycelium production, and also confers resistance to inhibition. Strain I873 was found to produce and to be resistant to the inhibitory substance, indicating that in its origin from IF strain I2 it had not lost SCPI.

Strains carrying SCPI in the autonomous state give rise spontaneously to UF spores and irradiation by u.v. significantly increases the frequency of such plasmid loss. Irradiation of IF strains, which carry the wild-type plasmid, increases the frequency of UF segregants up to tenfold, from a spontaneous frequency of $0.3 \%$ or less (Vivian \& Hopwood, 1970). The plasmid was lost so readily from the new donors described by Vivian \& Hopwood (1973) that meaningful estimates of the frequency were difficult to obtain; however, irradiation by u.v. certainly increased the proportion of segregants lacking the plasmid.

Table I shows that strain I873 gave rise spontaneously to about $5 \%$ of segregants unable to donate $c y s B^{+}$. This frequency was not affected by u.v. irradiation. Thus the modification of SCPI that gave rise to strain 1873 resulted in an increased frequency of spontaneous plasmid loss, but apparently abolished its susceptibility to curing by u.v.

In mixed cultures of IF with UF strains, nearly $100 \%$ of the spore progeny carrying the markers of the UF strain become converted to IF (Vivian, I97I). It was found that the modified plasmid in strain 1873 was also transferred very efficiently to a UF strain. In a mixed culture of 1873 with A450 (hisA I UF), all 40 of a sample of progeny carrying the his $A$ I marker showed evidence of having received the plasmid, since they inhibited UF tester strain I I9O. Such progeny, of which strain 1932 is an example, resembled the parent strain 1873 in their pattern of marker donation (Fig. 2) and in their instability (Table I), confirming that the novel behaviour of strain 1873 derived from a change in the plasmid rather than in a chromosomal gene.

The findings described in this section provided evidence that strain I 873 harboured a modified SCPI plasmid carrying the cysB locus, Moreover the strain behaved as a merodiploid, rather than a haploid strain with a chromosomal deletion corresponding to the insertion in the plasmid, since a haploid would not have [been expected] to lose its modified plasmid to yield viable UF derivatives (Broda, Beckwith \& Scaife, I964; Scaife \& Pekhov, 1964). Additional evidence for the interpretation of 1873 as a merodiploid was the finding that strain 1932, produced by transfer of the plasmid to a new host which could not have had a chromosomal deletion corresponding to the insertion in the plasmid, resembled the original strain 1873 in stability and donation characteristics. Strains carrying 


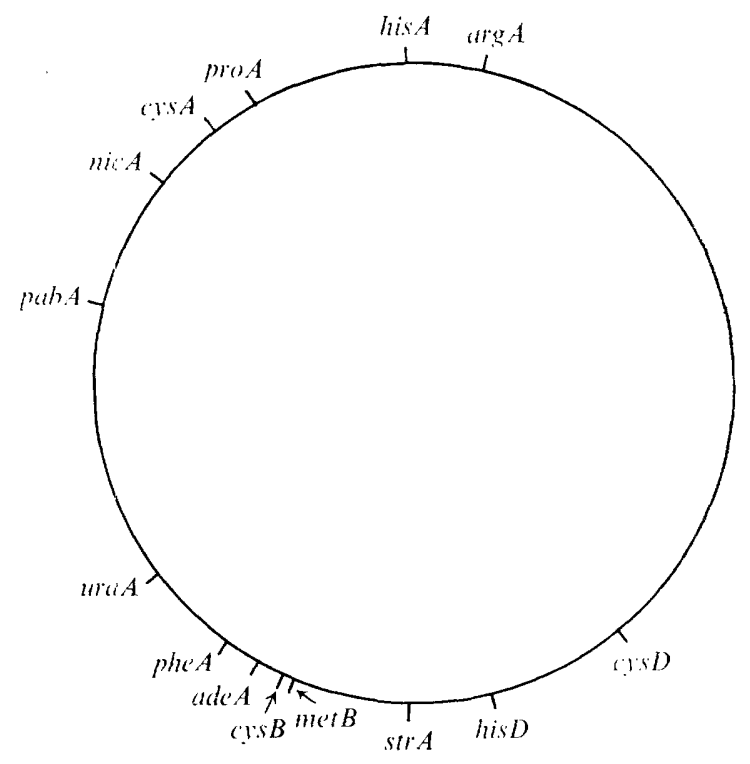

Fig. 3. Linkage map of Streptomyces coelicolor A3(2) showing loci referred to in this paper.

the new plasmid will be designated $\mathrm{SCPI}^{\prime}$ strains by analogy with $\mathrm{F}^{\prime}$ strains of Escherichia coli, and the plasmid will be called SCPI-cysB.

Inheritance of different markers from $S C P \mathrm{I}^{\prime}$ strains. Fig. 2 shows that the wild-type alleles of some other markers were donated by $\mathrm{SCPI}^{\prime}$ strains to UF strains with much lower frequencies than $c y s B^{+}$. In these plate-crosses, however, these markers were donated more frequently by the SCPI' strains than by the parent IF strain. In order to see whether the frequency of donation of such markers by SCPr' strains was related to their map position, a series of crosses was performed involving two such donors: the original isolate, 1873 (pheAI); and the secondary donor, strain 1932 (his $A \mathrm{I}$ ), derived by transfer of the SCPI$c y s B$ plasmid to a UF strain carrying his $A$. The two donors were cresced with UF strains carrying I 2 auxotrophic markers, either singly or in combinations of up to four. Selection was made for progeny inheriting the wild-type allele of each UF marker in turn, with the pheAr or his $A \mathrm{r}$ marker of the donor counter-selected. The yield of recombinants for each marker was expressed as a fraction of the number of progeny with the genotype of the UF parent, recovered on a suitably supplemented medium. Similar crosses were carried out with two IF strains carrying phe $A \mathrm{I}$ and his $A \mathrm{I}$ respectively.

The frequency of donation of each marker varied within a factor of about 20 in different experiments. The average values are given in Table 2 . The main conclusions to be drawn from these data are as follows. (I) The $c y s B$ locus was unique amongst the series of markers tested in the very high frequency of donation of its wild-type allele, which occurred more than a hundred times more frequently than donation of the wild-type alleles of any of the other loci. (2) Variations in the average donation frequencies of these other markers were considerable but were not systematically related to their proximity to $c y s B$. (3) With the striking exception of $c y s B^{+}$, differences in the donation frequencies of wild-type alleles by the $\mathrm{SCPI}^{\prime}$ compared with the IF strains were not very great; there was a tendency for higher donation frequencies by the SCPI' strains (up to a factor of about twenty), but for some alleles a somewhat higher figure was recorded for the IF strains. (4) There was no 


\section{Table 2. Frequency of donation of markers to UF strains}

Two SCPI-cysB strains and two IF strains, bearing counter-selected markers pheAI or hisAI, were crossed with UF strains bearing the markers in the left-hand column. Numbers in the body of the Table represent the proportions of progeny inheriting the wild-type (donor) allele of each UF marker.

\begin{tabular}{|c|c|c|c|c|}
\hline \multirow[b]{3}{*}{ UF marker } & \multicolumn{4}{|c|}{ Donor type } \\
\hline & \multicolumn{2}{|c|}{ SCPI $-c y s B$} & \multicolumn{2}{|c|}{ IF } \\
\hline & pheA I & his $A \mathrm{I}$ & pheA $\mathrm{I}$ & hisAI \\
\hline cysB6 & $9.3 \times 10^{-1}$ & $8.3 \times 10^{-1}$ & $1.6 \times 10^{-6}$ & $3.6 \times 10^{-5}$ \\
\hline ade $A v I 3$ & - & $7.4 \times 10^{-3}$ & - & $4.3 \times 10^{-4}$ \\
\hline pheAI & - & $7.4 \times 10^{-3}$ & - & $3.1 \times 10^{-4}$ \\
\hline uraA I & $\mathrm{I} \cdot 2 \times \mathrm{IO}^{-4}$ & $2.8 \times 10^{-4}$ & $4.2 \times 10^{-4}$ & $5.3 \times 10^{-4}$ \\
\hline$p a b A \mathbf{I}$ & $2 \cdot I \times 10^{-4}$ & $9.3 \times 10^{-5}$ & $3.1 \times 10^{-5}$ & $3.7 \times 10^{-5}$ \\
\hline cysAI 5 & $1.4 \times 10^{-3}$ & $4.5 \times 10^{-4}$ & $2 \cdot 2 \times 10^{-3}$ & $5.0 \times 10^{-4}$ \\
\hline pro $A \mathrm{I}$ & $9 \cdot 1 \times 10^{-5}$ & $1.6 \times 10^{-4}$ & $3.2 \times 10^{-5}$ & $5.9 \times 10^{-5}$ \\
\hline his $A \mathrm{I}$ & $I \cdot I \times I O^{-4}$ & - & $3.2 \times 10^{-5}$ & - \\
\hline $\arg A \mathrm{I}$ & $2.0 \times 10^{-4}$ & $8.4 \times 10^{-5}$ & $I \cdot I \times 10^{-4}$ & $2.7 \times 10^{-4}$ \\
\hline cys $D$ I 8 & $6.8 \times 10^{-5}$ & $3.5 \times 10^{-4}$ & $1 \cdot 4 \times 10^{-5}$ & $4.3 \times 10^{-5}$ \\
\hline his D3 & $5.2 \times 10^{-4}$ & $2.9 \times 10^{-3}$ & $6 \cdot 1 \times 10^{-6}$ & $6.9 \times 10^{-6}$ \\
\hline metB4 & $6 \cdot 1 \times 10^{-4}$ & $9.8 \times 10^{-4}$ & $4.3 \times 10^{-5}$ & $4.5 \times 10^{-5}$ \\
\hline
\end{tabular}

systematic difference in the frequency of inheritance of markers from the two SCPI' strains, confirming the conclusion reached above that they had the same constitution and therefore that the original isolate (I 873) was in fact a secondary (merodiploid) SCPI' strain rather than a primary (haploid) strain.

Table 2 indicates that only $c y s B$, out of the loci studied in these experiments, was carried on a fragment of chromosome inserted into SCPI in these donors. Mobilization of other markers, not borne on the plasmid, presumably involved a different mechanism.

The nearest loci to cys $B$ amongst those studied here are ade $A$ in a clockwise direction and $m e t B$ in an anti-clockwise direction. Since neither was donated at high frequency (Table 2) the maximum length of the chromosomal insertion carried on the SCPI-cys $B$ plasmid was the distance between these two loci, about $2 \%$ of the linkage map (Fig. 3).

Heterozygosity of progeny in crosses of $S C P_{\mathrm{I}^{\prime}}$ donors. On the hypothesis that the $c y s B^{+}$ donors were comparatively stable merodiploid strains harbouring a plasmid with a limited chromosomal insertion including $\mathrm{cys}^{+}$, at least some of the phenotypically $\mathrm{Cys}^{+}$progeny obtained by crossing such a donor with a $c y s B$ UF strain should also have been merodiploid; they should have given rise to $\mathrm{Cys}^{-}$derivatives, either spontaneously or after u.v. irradiation, with a frequency comparable with the frequency of production of non-donor derivatives by the $\mathrm{SCPI}^{\prime}$ donors themselves. This prediction was fulfilled. After exhaustive purification of such $\mathrm{Cys}^{+}$progeny by streaking and plating on minimal medium, a minority of $\mathrm{Cys}^{-}$ colonies arose (Table 3: strain I). Not only was the frequency of $\mathrm{Cys}^{-}$derivatives of such strains within the range of frequencies of non-donor derivatives of the $\mathrm{SCPI}^{\prime}$ strains (Table I), but the frequency was similarly not affected by u.v. irradiation.

Transfer of the SCPI-cysB plasmid between strains A3(2) (Streptomyces coelicolor) and I326 (S. lividans). Hopwood \& Wright (1973a) showed SCPI to be transferable to wildtype strain 1326 , which behaved as a UF-like strain in being sensitive to inhibition by IF cultures of $S$. coelicolor A3(2). About I to $3 \%$ of the spores of strain I 326 were converted to IF by growth with IF $S$. coelicolor A3(2). No transfer of SCPI back from I 326 to A3(2) was detected; however, the test available, a visual appraisal of inhibition of a sensitive UF 
Table 3. Heterozygosity of $\mathrm{Cys}^{+}$progeny of crosses involving strains carrying the $S C P$ I-cys $B$ plasmid

\begin{tabular}{|c|c|c|c|c|c|c|}
\hline & Origin of & & Survival & Totalno of & Cys & colonies \\
\hline & $\mathrm{Cys}^{+}$strains $^{*}$ & Treatment & $(\%)$ & colonies & Number & Percentage \\
\hline I & $\left(\mathrm{A}_{3}(2) \rightarrow \mathrm{A}_{3}(2)\right)$ & Control & $(100)$ & 197 & 15 & $7 \cdot 6$ \\
\hline & & U.V. & I 4 & 196 & 15 & $7 \cdot 7$ \\
\hline II $\dagger$ & $\left(\mathrm{A}_{3}(2) \rightarrow 1326\right)$ & Control & $(100)$ & 383 & 25 & $6 \cdot 5$ \\
\hline & & U.V. & 19 & 348 & $2 I$ & 6.0 \\
\hline III & $\left(1326 \rightarrow A_{3}(2)\right)$ & Control & $(100)$ & 378 & 19 & $5 \cdot 0$ \\
\hline & & U.V. & $2 \cdot 2$ & 395 & 18 & $4 \cdot 6$ \\
\hline
\end{tabular}

* See Fig. 3. $†$ Average of two strains.

culture, had limited resolution and would not have detected a very low level of transfer. Once in strain I 326, SCPI was transferred to derivatives of $\mathrm{I} 326$ with a frequency approaching $100 \%$, just as it was between derivatives of $\mathrm{A3}(2)$.

From amongst the survivors of NTG mutagenesis of strain 1326, auxotrophs were isolated, one of which, strain I697, was a cysteine-requiring mutant (cys-3) with a phenotype resembling that of $c y s B$ mutants in Streptomyces coelicolor A3(2); that is, it grew on thiosulphate, but not on metabisulphite, as alternatives to cysteine. In crosses of strain 1697 with I873, a considerable proportion of the progeny recovered on MM supplemented with cysteine were found to be prototrophic; moreover, in a sample of progeny characterized in detail there was a complete correlation between prototrophy and the presence of SCPI as deduced from the IF-like reaction of the cultures in inhibiting the parent strain I326. Out of 78 progeny, $17(22 \%)$ were $\mathrm{Cys}^{+}$and plasmid-bearing, while 6I were $\mathrm{Cys}^{-}$and lacked the plasmid; in this experiment there was an unusually high frequency of plasmid transfer between strains A3(2) and 1326.

Two randomly selected $\mathrm{Cys}^{+}$progeny were purified by successive streaking and tested for heterozygosity in respect of the $\mathrm{Cys}^{+}$phenotype. Both showed unambiguous evidence of $\mathrm{Cys}^{-}$segregation, which was repeated over three successive rounds of $\mathrm{Cys}^{+}$single colony purification; the results in Table 3 (strain II) refer to the last round of this procedure. It is apparent that the frequency of $\mathrm{Cys}^{-}$segregation from these strains was the same as from the heterozygous $\mathrm{Cys}^{+}$strains produced by transferring the SCPI-cysB plasmid between derivatives of $\mathrm{A3}$ (2), and was similarly not affected by u.v. irradiation.

Further evidence for the merodiploid nature of strains produced by transfer of the SCPI-cys $B$ plasmid to derivatives of strain $\mathrm{I} 326$ was provided by transferring the plasmid back to a derivative of $\mathrm{A} 3(2)$. To prepare a suitable donor for this test, strain 1873 was crossed with strain 1703, a histidine-requiring mutant (his-1) of strain 1326, and Hisprogeny were recovered on MM supplemented with histidine. Some of the colonies tested showed evidence of SCPI inheritance by their inhibition of strain 1326 and one of these (strain I926) was chosen at random and crossed with strain A694, the UF cysB6 derivative of $\mathrm{A3}(2)$, with selection on $\mathrm{MM}$. The frequency of $\mathrm{Cys}^{+}$progeny in such crosses was very low: $6 \times 10^{-6}$ in one experiment and $8 \times 10^{-7}$ in another in respect of the cysB 6 parent. Five of the Cys ${ }^{+}$progeny were chosen at random and purified by three successive streakings; all five strains continued to give rise to $\mathrm{Cys}^{-}$colonies. Moreover, a quantitative study of two of them showed a segregation frequency (Table 3: strain III) not significantly different from that of $\mathrm{Cys}^{+}$progeny produced by a direct cross of 1873 with A694 (Table 3 : strain I). 
Table 4. Proportion of $\mathrm{Cys}^{+}$progeny in crosses between A3(2) donors and A3(2) or 1326 UF recipients

The donor strains carried hisAI for counter-selection and the recipients carried a cys $B$ mutation.

$\begin{array}{ccc}\begin{array}{c}\text { Plasmid status of } \\ \text { donor strain }\end{array} & \begin{array}{c}\text { Wild-type from which } \\ \text { recipient strain was } \\ \text { derived }\end{array} & \begin{array}{c}\text { Proportion of Cys } \\ \text { progeny recovered on } \\ \text { MM }+ \text { cysteine }\end{array} \\ \text { SCPI-cys } B & \mathrm{~A} 3(2) & 8.3 \times 10^{-1 *} \\ \text { SCPI-cysB } & 1326 & 8.0 \times 10^{-2 *} \\ \text { NF } & \mathrm{A} 3(2) & 3.5 \times 10^{-2} \dagger \\ \text { NF } & 1326 & 8.5 \times 10^{-7} \dagger \\ * \text { Average of } 3 \text { crosses. } & \dagger \text { Average of } 2 \text { crosses. }\end{array}$

Thus the SCPI-cysB plasmid was apparently unaffected by its sojourn in another wild-type strain.

The special nature of the $\mathrm{Cys}^{+}$progeny produced in crosses involving the SCPI-cys $B$ plasmid was also indicated by a comparison of the relative frequencies of $\mathrm{Cys}^{+}$progeny in crosses of an SCPI' strain and an NF strain with cysB UF strains of A3(2) and of 1326 (Table 4). The donor strains, each carrying the chromosomal marker hisAI for counter-selection, were $\mathrm{A} 423(\mathrm{NF})$ and $1932\left(\mathrm{SCPI}^{\prime}\right)$. Prototrophic progeny of the crosses involving the NF donor were selected on MM and their frequency was related to the colony count on MM supplemented with cysteine, which recovered the recipient genotype. Progeny of the crosses involving the $\mathrm{SCPI}^{\prime}$ donor were recovered on $\mathrm{MM}$ supplemented with cysteine, and a sample of the resulting colonies was tested for $\mathrm{Cys}^{+}$or $\mathrm{Cys}^{-}$phenotype. The results (Table 4) show that, when the donor carried the SCPI-cys $B$ plasmid, the frequency of $\mathrm{Cys}^{+}$progeny yielded by the 1326 recipient was only tenfold lower than the yield from the $\mathrm{A} 3(2)$ recipient. In sharp contrast, nearly $10^{5}$-fold fewer progeny were obtained from a 1326 recipient compared with an $\mathrm{A} 3(2)$ recipient when the donor was an NF strain.

It was found that the SCPI-cysB plasmid, like the wild-type SCPI (Hopwood \& Wright, 1973), was transferred very efficiently between derivatives of strain 1326 . In a cross of SCPI' strain I 926 (his-1) with UF strain I697 (cys-3), 72 out of a sample of I00 progeny recovered on MM supplemented with cysteine were prototrophic and plasmid-carrying; this frequency was within the range found in comparable crosses between derivatives of A3(2).

Derivatives of the $S C P \mathrm{I}-\mathrm{cys} B$ plasmid. Amongst the non-donors derived from the $\mathrm{SCPI}^{\prime}$ strains (Table I) and the $\mathrm{Cys}^{-}$segregants from heterozygous $\mathrm{Cys}^{+}$strains (Table 3), the great majority showed no evidence of the presence of the plasmid since they failed to inhibit UF strains; presumably they were UF strains derived by plasmid loss. However, about $10 \%$ of them still inhibited UF strains, indicating the presence of SCPI functions. In both kinds of strain the plasmid appeared still to be autonomous since it was transferred readily to UF strains and was lost with an easily detected frequency to yield UF strains. The most likely explanation for both kinds of strain is the loss by the SCPI-cys $B$ plasmid of the chromosomal insertion, or at least of that part carrying the $c y s B$ locus, perhaps by some kind of internal crossing-over or 'loop-out'. Strains apparently carrying the normal plasmid (IF strains) were derived from the donors described by Vivian \& Hopwood (1973), and a similar explanation was proposed to account for the origin of such derivatives. 


\section{DISCUSSION}

The results above provide extremely strong evidence of the isolation of a strain of Streptomyces coelicolor A3(2) analogous with a merodiploid F-prime strain of Escherichia coli $\mathrm{KI} 2$ : that is a strain carrying an autonomous plasmid into which a piece of chromosome carrying one recognized marker $\left(\operatorname{cys} B^{+}\right)$had been inserted. Much of the evidence derived from the results of crosses between derivatives of $S$. coelicolor $\mathrm{A} 3(2)$, in particular the findings that donation of the $c y s B^{+}$allele to a $c y s B$ recipient occurred with the same very high frequency as donation of the plasmid itself, and that the $\mathrm{Cys}^{+}$strains so produced were heterozygous at the $c y s B$ locus.

Further support for the hypothesis was provided by the results of crosses with derivatives of Streptomyces lividans strain I326, a strain already shown to be UF-like and to receive the wild-type SCPI plasmid (Hopwood \& Wright, 1973 $a$ ). In a cross of a cys $B$ mutant of 1326 with $S$. coelicolor A3(2) carrying the presumptive SCPI-cys $B$ plasmid, all progeny that had received the plasmid were converted to $\mathrm{Cys}^{+}$heterozygotes. Evidently the production of $\mathrm{Cys}^{+}$progeny in such a cross did not require the integration of the $c y s B^{+}$allele from strain A3(2) into the 1326 genome. Thus, the frequency of Cys ${ }^{+}$progeny when I 326 was the recipient was reduced only by a comparatively small factor (about I0) compared with the yield when A3(2) was the recipient, and this could be accounted for by the reduced frequency of plasmid transfer. In contrast, when transfer followed by integration by crossing-over was required for the production of $\mathrm{Cys}^{+}$progeny, as when an NF donor was used, the yield was reduced by a factor of nearly $10^{5}$, indicating considerable lack of homology between the A3(2) and 1326 genomes and confirming the autonomous status of the $c y_{s} B^{+}$allele in the SCPI' strain.

The SCPI' strain described here does not, at present, illuminate the nature of the donors described by Vivian \& Hopwood (I973), which were also postulated to be SCPI' strains but harbouring plasmids carrying unmarked regions of the chromosome. In the present work the donation frequencies of markers not borne on the plasmid, but closely linked to $c y s B$, were very much lower than those of markers close to the presumed plasmid insertion in the donors of Vivian \& Hopwood (1973), who discussed donor crossing-over in a region of homology between the postulated $\mathrm{SCPI}^{\prime}$ and the chromosome as a possible mechanism leading to marker transfer. In the case of the SCPI-cysB strain described in the present paper, the frequencies of marker donation (except for $c y s B$ ) were not always above those given by IF strains, in which the autonomous SCPI plasmid probably interacts transiently with the chromosome at various points (Hopwood et al. 1973). Thus a more detailed study of further markers in the vicinity of $c y s B$ will be required to distinguish, in the presence of this non-specific transfer, any specific transfer mode attributable to SCPI-cysB.

The present work has confirmed the conclusion from studies of the wild-type SCPI plasmid (Hopwood \& Wright, I973a) that transfer back from Streptomyces lividans I326 to $S$. coelicolor occurs at a much lower frequency than from $\mathrm{A3}(2)$ to $\mathrm{I} 326$. Using the selective system provided by the presence of the $c y s B^{+}$allele on the substituted plasmid it was possible to detect a reverse transfer frequency of around $10^{-6}$, whereas in the forward direction, from $\mathrm{A}_{3}(2)$ to 1326 , transfer of the substituted plasmid, like that of the wild-type plasmid (Hopwood \& Wright, I973a), usually occurred with a frequency of between I and $5 \%$, and sometimes even higher. Although restriction-modification was not excluded by Hopwood \& Wright (I973a) as an explanation for the lack of efficient transfer of SCPI from I 326 to A3(2), it was not detected by the bacteriophage test adopted. Assuming the absence of such a system, the poor capacity of 1326 strains carrying SCPI to function as plasmid 
donors to $\mathrm{A} 3$ (2), in contrast with their good donation to 1326 derivatives, indicates a possible strain-specificity of the conjugation process analogous with that in Gram-negative eubacteria, in which inter-specific plasmid transfer is usually less efficient than transfer between closely related strains.

As pointed out by Hopwood \& Wright (I973a), the availability of a selective system such as that offered by a plasmid bearing a gene conferring prototrophy should allow the detection of widespread inter-specific plasmid transfer if it occurs in the genus Streptomyces. Already the isolation of a strain carrying a substituted plasmid, and the inter-specific transfer of the plasmid, have several important implications, both for the experimental genetics of the organism and for practical strain improvement. Hitherto, complementation and dominance testing in Streptomyces coelicolor have depended on the recovery of transient merodiploids, called heteroclones (Sermonti, Mancinelli \& Spada-Sermonti, I960; Hopwood, Sermonti \& Spada-Sermonti, I963) produced from the zygotes in parallel with haploid recombinants (Hopwood, I967). Heteroclones have been used successfully in complementation studies of auxotrophic (Hopwood \& Sermonti, I962; Engel, I973) and radiationsensitive mutations (Harold \& Hopwood, 1970), but they are not ideal for this purpose and have so far not been applicable to complementation tests of morphogenetic mutations, for which such tests would be highly desirable (Chater, 1972; Chater \& Hopwood, 1973). The comparatively stable merodiploids produced by the inheritance of substituted plasmids should be satisfactory for functional genetic tests involving any class of mutation. Their usefulness will be realized as soon as it is possible to isolate easily $\mathrm{SCPI}^{\prime}$ strains with insertions of particular groups of chromosomal loci into the plasmid.

The potential utility of substituted plasmids in strain improvement was outlined by Hopwood (I972). In brief, the significance of inter-specific transfer of a substituted plasmid may lie in the possibility offered by this technique for transferring a specific group of genes from one strain to another to give a comparatively stable merodiploid in which the "foreign" genes may be expressed without the necessity for integration by crossing-over into the chromosome of the new host, as in strain 1326 in the present study. The strains described in the present paper were somewhat unstable, yielding about $5 \%$ of derivatives lacking the plasmid after cultivation on non-selective solid media, but the plasmid could be retained indefinitely by growth on a medium selective for the plasmid-borne marker. We can expect that strains carrying different substituted plasmids will vary in their stability, some probably being more stable than those described here.

It is a pleasure to thank Mrs Helen Tovell for excellent assistance with the experimental work described in this paper.

\section{REFERENCES}

Adelberg, E. A. \& Burns, S. N. (1960). Genetic variation in the sex factor of Escherichia coli. Journal of Bacteriology 79, $32 \mathrm{I}-330$.

Broda, P., Beckwith, J. R. \& SCAIfE, J. (1964). The characterization of a new type of F-prime factor in Escherichia coli K-I2. Genetical Research 5, 489-494.

Campbell, A. (1962). Episomes. Advances in Genetics 11, 10I-145.

ChATER, K. F. (1972). A morphological and genetic mapping study of white colony mutants of Streptomyces coelicolor. Journal of General Microbiology 72, 9-28.

Chater, K. F. \& Hopwood, D. A. (1973). Differentiation in actinomycetes. In Microbial Differentiation, pp. 143-I60. Edited by J. M. Ashworth and J. E. Smith. 23rd Symposium of the Society for General Microbiology. Cambridge University Press.

Delić, V., Hopwood, D. A. \& FrIEND, E. J. (1970). Mutagenesis by $N$-methyl- $N^{\prime}$-nitro- $N$-nitrosoguanidine (NTG) in Streptomyces coelicolor. Mutation Research 9, 167-182. 
ENGEL, P. P. (1973). Genetic control of tryptophan biosynthesis in Streptomyces coelicolor. In Genetics of Industrial Micro-organisms, pp. I25-I47. Edited by Z. Vaněk, Z. Hoštálek and J. Cudlín. Prague: Academia.

Harold, R. J. \& Hopwood, D. A. (1970). Ultraviolet-sensitive mutants of Streptomyces coelicolor. I. Phenotypic characterisation. Mutation Research 1o, 427-438.

Hopwood, D. A. (1967). Genetic analysis and genome structure in Streptomyces coelicolor. Bacteriological Reviews 31, 373-403.

Hopwood, D. A. (1972). Genetics of the actinomycetales. In Actinomycetales: Characteristics and Practical Importance, pp. I3I-I 53. Edited by G. Sykes and F. A. Skinner. London: Academic Press.

Hopwood, D. A., Chater, K. F., Dowding, J. E. \& Vivian, A. (1973). Advances in Streptomyces coelicolor genetics. Bacteriological Reviews (in the Press).

Hopwood, D. A., Harold, R. J., Vivian, A. \& Ferguson, H. M. (1969). A new kind of fertility variant in Streptomyces coelicolor. Genetics 62, 461-477.

Hopwood, D. A. \& SermontI, G. (1962). The genetics of Streptomyces coelicolor. Advances in Genetics II, 273-342.

Hopwood, D. A., Sermonti, G. \& Spada-Sermonti, I. (1963). Heterozygous clones in Streptomyces coelicolor. Journal of General Microbiology 30, 249-260.

Hopwood, D. A. \& WRIGHT, H. M. (I973a). Transfer of a plasmid between Streptomyces species. Journal of General Microbiology 77, I87-195.

Hopwood, D. A. \& WRIGHT, H. M. (I973b). Interspecific transfer of a plasmid carrying chromosomal markers in Streptomyces. Proceedings of the 13th International Congress of Genetics. Genetics 74, Si $19-120$.

JACOB, F. \& AdeLBERG, E. A. (I959). Transfert de caractères génétiques par incorporation au facteur sexuel d'Escherichia coli. Comptes rendues de l'Académie de sciences 249, r89-19I.

Krasilnikov, N. A. (1965). Biology of Separate Groups of Actinomycetes. Moscow: Nauka.

Lomovskaya, N. D., Mrrtumian, N. M., GostimskaYa, N. L. \& DanilenKo, V. N. (1972). Characterization of temperate actinophage $\varnothing_{3} \mathrm{I}$ isolated from Streptomyces coelicolor A3(2). Journal of Virology 9 , 258-262.

Puglia, A. M., Spada-Sermonti, I., Basile, S., Misuraca, F. \& Sermonti, G. (1973). Infectious transfer of a fertility factor in Streptomyces coelicolor. Genetical Research 2r, 107-113.

SCAIFE, J. \& PeKhov, A. P. (I964). Deletion of chromosomal markers in association with F-prime factor formation in Escherichia coli K-12. Genetical Research 5, 495-498.

Sermonti, G. \& Casciano, S. (1963). Sexual polarity in Streptomyces coelicolor. Journal of General Microbiology 33, 293-301.

Sermonti, G., Mancinelli, A. \& Spada-Sermonti, I. (i960). Heterozygous clones ('heteroclones') in Streptomyces coelicolor A3(2). Genetics 45, 669-672.

Vivian, A. (1971). Genetic control of fertility in Streptomyces coelicolor A3(2): plasmid involvement in the interconversion of UF and IF strains. Journal of General Microbiology 69, 353-364.

VIVIAN, A. \& Hopwood, D. A. (1970). Genetic control of fertility in Streptomyces coelicolor A3(2): the IF fertility type. Journal of General Microbiology 64, IOI-I I7.

Vivian, A. \& Hopwood, D. A. (1973). Genetic control of fertility in Streptomyces coelicolor A3(2): new kinds of donor strains. Journal of General Microbiology 76, 147-162. 